\title{
PELATIHAN PEMBUATAN DEODORAN DARI BAHAN ALAMI DAN PERINTISAN SEBAGAI HOME INDUSTRI
}

\author{
Ika Nur Fitriani ${ }^{1}$, Ismi Rahmawati ${ }^{1}$, Dewi Ekowati ${ }^{1}$, Dwi Ningsih ${ }^{1}$, Isna Jati Asiyah ${ }^{1}$ \\ ${ }^{1}$ Fakultas Farmasi, Universitas Setia Budi Surakarta \\ Email: ika.nurfitriani93@gmail.com
}

\begin{abstract}
ABSTRAK
Bau badan banyak dikeluhkan oleh masyarakat di daerah tropis seperti Indonesia. Bau badan merupakan salah satu masalah yang mengganggu kehidupan sehari-hari. Bau tidak sedap pada tubuh sering kali membuat seseorang merasa kurang percaya diri. Salah satu cara untuk mengatasi masalah bau badan adalah dengan memakai deodoran. Deodoran pada umumnya mengandung bahan kimia yang dapat menyebabkan resiko iritasi kulit. Oleh karena itu perlu suatu solusi untuk mengatasi masalah tersebut yaitu dengan membuat deodorant dengan bahan alami. Sasaran dalam kegiatan pengabdian kepada masyarakat ini adalah warga masyarakat Bibis Luhur. Kegiatan ini berupa pelatihan pembuatan deodorant dari bahan alami. Tujuan kegiatan ini adalah memberdayakan sumber daya alam secara optimal sehingga dapat mendorong perekonomian masyarakat dengan jalan perintisan home industry deodoran.
\end{abstract}

Kata kunci : Deodoran, herbal, pelatihan

\section{PENDAHULUAN}

Bau badan banyak dikeluhkan oleh masyarakat di daerah tropis seperti Indonesia. Bau badan merupakan salah satu masalah yang mengganggu kehidupan sehari-hari. Bau tidak sedap pada tubuh sering kali membuat seseorang merasa kurang percaya diri. Aroma yang tidak sedap tersebut biasanya muncul ketika seseorang mulai berkeringat. Sebenarnya keringat merupakan usaha untuk mengatur suhu tubuh manusia. Keringat mengandung air, garam, dan zat sisa dari dalam tubuh. Keringat ada yang mengeluarkan bau tetapi ada juga yang tidak. Biasanya bau yang tidak sedap timbul bersama bau badan yang disebabkan karena kurang menjaga kebersihan badan dan adanya bakteri yang menguraikan keringat menjadi zat yang berbau kurang sedap.

Keringat dihasilkan oleh dua kelenjar yaitu ekrin dan apokrin. Kelenjar ekrin memproduksi keringat bening dan tidak berbau, biasanya muncul di tangan, sedangkan kelenjar apokrin terdapat di tempat khusus seperti ketiak dan hidung. Bau badan dapat diatasi antara lain dengan sediaan deodoran yang dioleskan pada bagian ketiak.

Salah satu cara untuk mengatasi masalah bau badan adalah dengan menggunakan deodoran. Meski begitu, memiliki produk deodoran yang cocok memang bukan perkara mudah. Apalagi, bagi yang termasuk orang-orang yang punya kulit sensitif. Kandungan bahan kimia yang cukup tinggi terkadang bisa membuat kulit teriritasi.

Adanya resiko iritasi pada pengunaan deodoran yang mengandung bahan kimia yang cukup tinggi maka perlu suatu solusi untuk mengatasi masalah tersebut yaitu dengan membuat sendiri deodorant dengan bahan alami mengurangi risiko iritasi kulit ketiak selain itu juga bisa menghemat pengeluaran.

Tujuan dari usaha pembuatan deodoran dengan bahan alami ini adalah untuk memberdayakan sumber daya alam secara optimal dan menghasilkan produk sendiri yang dapat untuk dipakai sendiri. Deodoran merupakan produk yang sangat banyak dibutuhkan masyarakat, sehingga sangat memungkinkan untuk dikembangkan produksinya dalam skala industri rumah tangga untuk meningkatkan perekonomian masyarakat. 
Sasaran dalam kegiatan pengabdian kepada masyarakat ini adalah warga masyarakat Bibis Luhur. Bibis Luhur adalah sebuah perkampungan yang berada tepat di belakang lokasi kampus Universitas Setia Budi. Kampung dengan kepadatan penduduk yang tinggi dan mayoritas warga kampung adalah buruh pabrik dengan tingkat penghasilan yang rendah. Dengan tingkat perekonomian yang rendah, secara tidak langsung juga berdampak terhadap kesadaran akan perawatan kesehatan dan estetika yang masih tergolong rendah. Sesuai dengan RENSTRA atau Rencana Strategis Pengabdian kepada Masyarakat tahun 2016-2020 yaitu optimalisasi potensi sumber daya masyarakat, maka akan diadakan pelatihan pembuatan deodoran di masyarakat untuk meningkatkan estetika, dan mendorong perekonomian masyarakat dengan jalan perintisan home industry deodoran.

\section{METODE PELAKSANAAN}

Permasalahan yang dihadapi mitra adalah tingkat perekonomian yang rendah serta pengetahuan dan kesadaran akan perawatan tubuh yang masih tergolong rendah. Solusi yang ditawarnak pada Mitra yaitu perlu pelatihan dan motivasi untuk menciptakan peluang usaha rumahan (home industry) dengan produk yang dapat digunakan untuk menjaga estetika (mencegah bau badan) sehari-hari sekaligus menambah pendapatan penduduk melalui pembuatan deodorant herbal pencegah bau badan.

Pada pelaksanaan pengabdian ini, akan dilakukan penyuluhan, pelatihan dan pemberian alat produksi. Langkah-langkah yang dilakukan sebagai berikut :

1. Sosialisasi

Masyarakat mitra akan diberikan penjelasan mengenai pentingnya penggunaan deodorant, potensi pembuatan deodorant herbal, dan memberikan motivasi untuk menciptakan peluang usaha rumahan (home industry) dengan produk berupa deodorant.

2. Pelatihan pembuatan deodorant herbal

Masyarakat mitra akan diberikan pengetahuan dan pelatihan cara pembuatan deodoran yang komposisi zat aktifnya berasal dari tanaman, serta dilakukan pendampingan kelompok ibu rumah tangga dalam proses pembuatan deodorant. Pada tahap ini, masyarakat juga akan diberikan alat-alat penunjang dalam produksi deodorant.

3. Evaluasi

Kegiatan evaluasi bertujuan untuk melihat keberhasilan Program Pengabdian bagi Masyarakat dalam pelatihan pembuatan produk deodoran herbal. Kegiatan ini juga bertujuan untuk mengidentifikasi permasalahan atau hambatan yang terjadi selama proses persiapan hingga pelaksanaan kegiatan penggabdian tersebut, serta menampung masukan dan saran agar dikemudian hari bisa lebih baik lagi dalam pelaksanaannya.

Peserta kegiatan adalah ibu-ibu di RW 22 RT 03 Bibis Luhur, Nusakan Surakarta. Peserta dibekali pengetahuan dan ketrampilan dalam pembuatan deodorant dari bahan herbal yang dapat dibuat di rumah untuk meningkatkan estetika dan diharapkan dapat meningkatkan perekonomian masyarakat.

\section{HASIL DAN PEMBAHASAN}

Kegiatan pengabdian masyarakat pelatihan pembuatan deodoran dari bahan herbal telah dilakukan di Bibis Luhur RW 22 RT 03, Nusukan, Surakarta pada tanggal 15 Agustus 2018. Kegiatan pengabdian diawali dengan komunikasi dengan pihak kelurahan dan RW sebagai tempat pengabdian. Sebelum dilakukan pelatihan pembuatan deodoran terlebih dahulu dilakukan orientasi untuk mendapatkan formula yang optimal, dilanjutkan dengan pelatihan pembuatan deodoran dari bahan herbal yang dipraktekkan bersama dengan ibu-ibu 
warga RW 22 RT 03 Nusukan. Program kegiatan pengabdian masyarakat ini dihadiri oleh 30 peserta warga RW 22 Kelurahan Nusukan. Untuk mempermudah peserta memahami materi pelatihan dilengkapi dengan leaflet formula bahan balsam dan cara mengerjakannya. Formula deodoran stik adalah sebagai berikut:
1.
Minyak VCO
$: 2 \mathrm{sdm}$
2.
Shea butter
3.
Beeswax
4.
Baking soda
$: 2 \mathrm{sdm}$
4.
Tepung maizena
: 10 butir
5.
Aroma
$: 1 / 4 \mathrm{sdt}$
6.

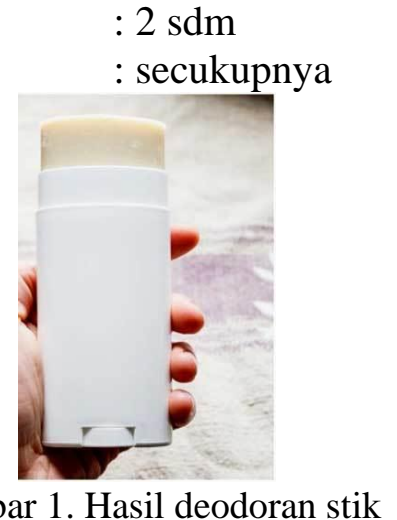

Hasil dan luaran yang telah dicapai yaitu:

a. Sosialisasi

Sosialisasi diadakan untuk memberikan gambaran model pembuatan deodorant kepada para peserta. Metode pendekatan yang digunakan adalah ceramah dan diskusi. Ceramah dilakukan oleh pemateri tim pengabdi. Ceramah berisi pemberian materi tentang manfaat deodoran dengan bahan aktif herbal yang secara mudah diperoleh dan relatif aman karena berasal dari tanaman, dan diberikan pelatihan pembuatannya. Ibu-ibu dikenalkan bahan pembuatan deodorant beserta kegunaan masing-masing bahan yaitu: VCO, baking soda, beeswax, tepung maizena, sheer butter, dan minyak esensial. Peserta dapat bertanya langsung hal yang belum dipahami saat diskusi. Tim pengabdi juga memanfaatkan sesi diskusi untuk mengetahui pengetahuan awal para peserta mengenai pembuatan deodorant.

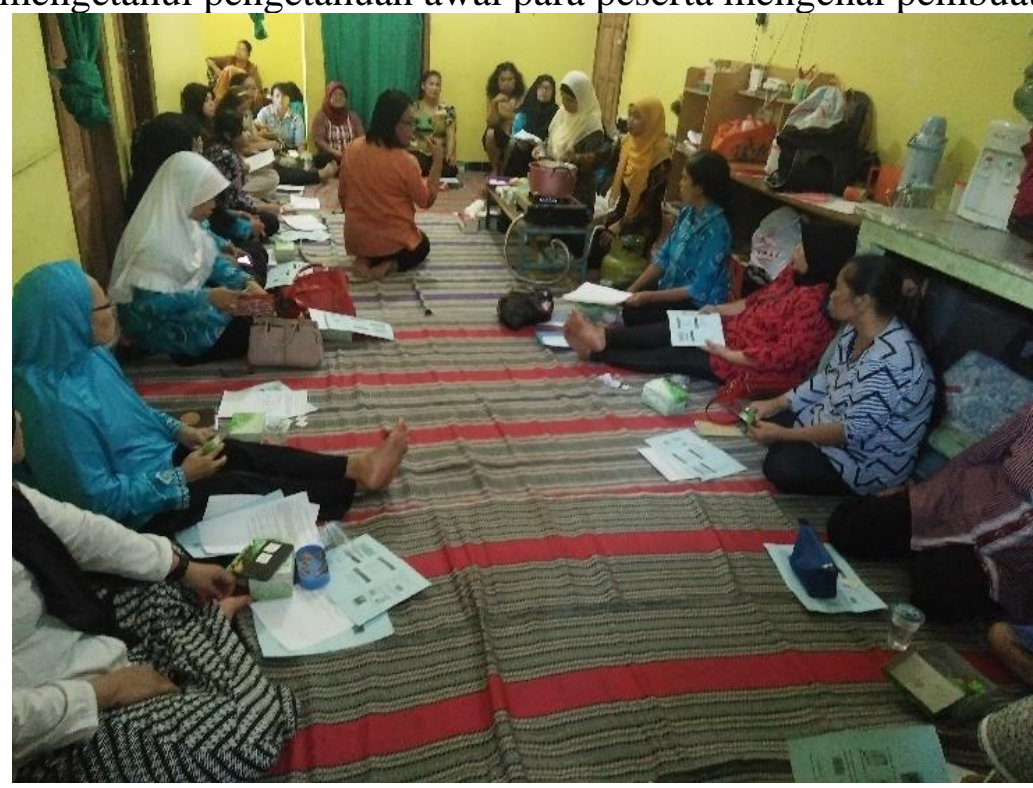

Gambar 2. Acara sosialisasi 
b. Demonstrasi dan praktik langsung

Pelatihan pembuatan deodoran herbal sebagai rintisan home industri diawali dengan menghibahkan peralatan berupa kompor, tabung gas, panci, pengaduk, timbangan, wadah deodoran, dan bahan-bahan pembuat deodoran yang nantinya diharapkan warga bisa membuat deodoran tersebut untuk kepentingan sendiri dan harapannya bisa memproduksi dalam jumlah besar untuk diperdagangkan sehingga bisa menambah penghasilan.

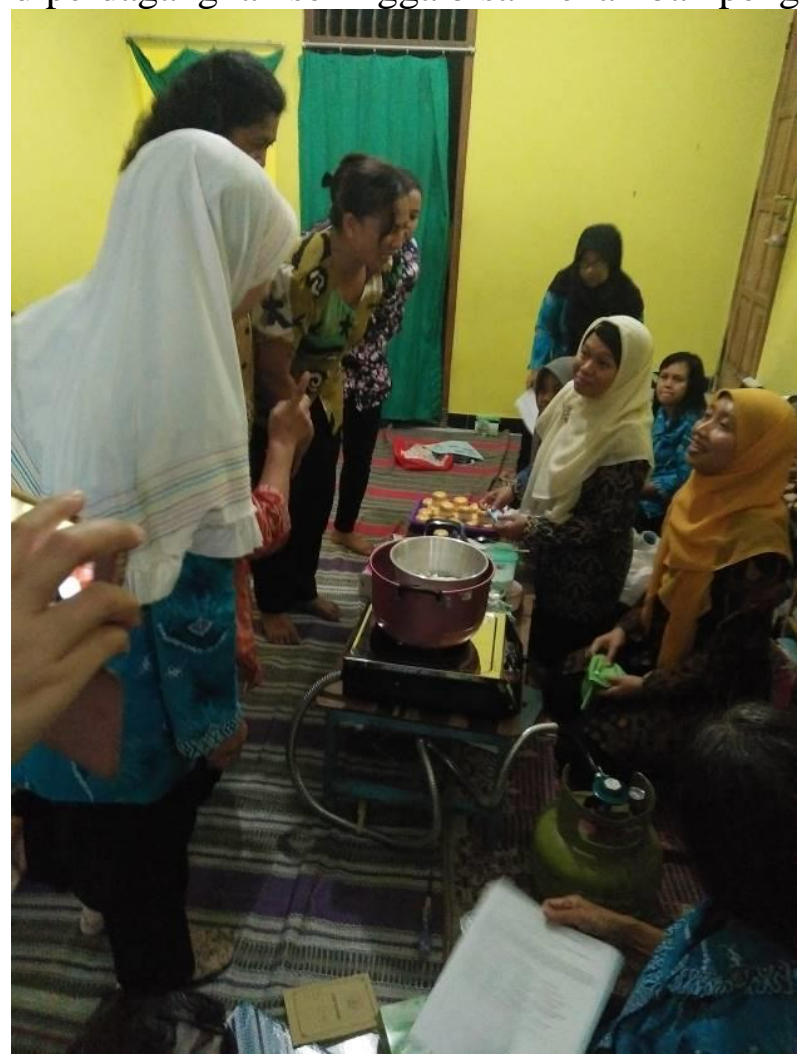

Gambar 3. Pelatihan pembuatan deodoran

Acara diteruskan dengan pembagian leaflet pembuatan deodorant herbal kepada peserta pelatihan. Materi pelatihan yang diberikan yaitu proses pembuatan deodoran herbal alami. Tahap pembuatan deodorant: (1) campurkan minyak kelapa padat, shea butter, dan beeswax dalam sebuah mangkuk kaca. Lalu, letakkan mangkuk kaca itu ke dalam panci ukuran medium yang sudah diisi dengan air; (2) didihkan air dalam panci menggunakan api kecil. Ketika air mendidih, pastikan minyak kelapa, beewax, dan shea butter meleleh dengan sempurna sambil terus diaduk-aduk agar merata.; (3) setelah semua bahan meleleh sempurna, matikan api dan campurkan baking soda serta tepung maizena. Pastikan telah dicampur secara merata dan berulang kali. Sebab, campuran tadi akan memadat saat mendingin dan tidak diaduk. Sebelum memadat, jangan lupa tambahkan beberapa tetes minyak esensial; (4) tempatkan cairan deodoran dalam sebuah wadah. Lalu diamkan sejenak sampai cairan tersebut memadat sempurna. Deodoran hasil pembuatan hasilnya akan sama seperti deodorant yang dijual di pasaran. Selanjutnya ibu-ibu praktek membuat deodoran yang dilakukan secara mandiri dengan pendampingan. 

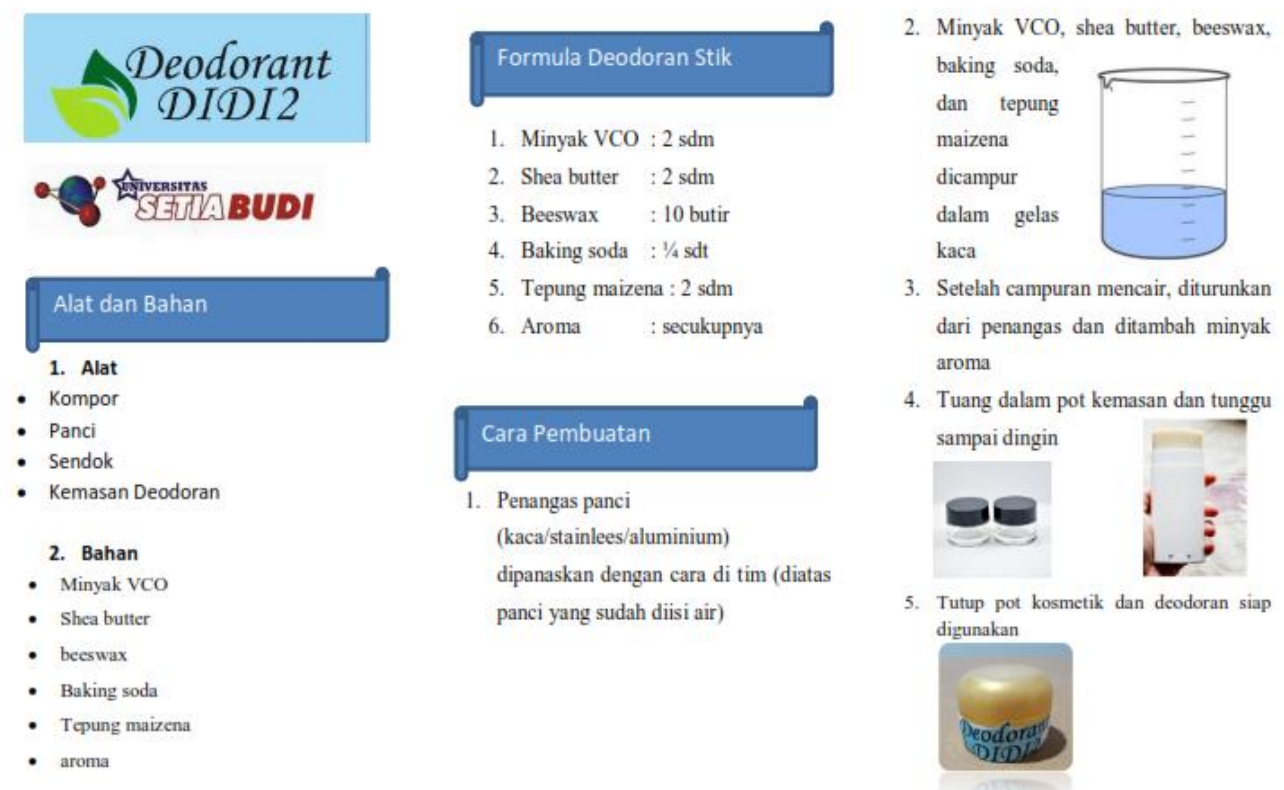

Gambar 4. Leaflet pembuatan deodoran

Ketertarikan dan peran aktif dari para peserta terhadap pelatihan pembuatan deodoran herbal berbentuk stik ini diharapkan bisa menjadi peluang usaha rumah tangga di lingkungan RW 22 Kelurahan Nusukan, yang merupakan salah satu target luaran dalam kegiatan pengabdian pelatihan pembuatan deodorant berbahan herbal. Dampak positif yang dihasilkan pasca kegiatan adalah mitra dapat membuat deodoran herbal.

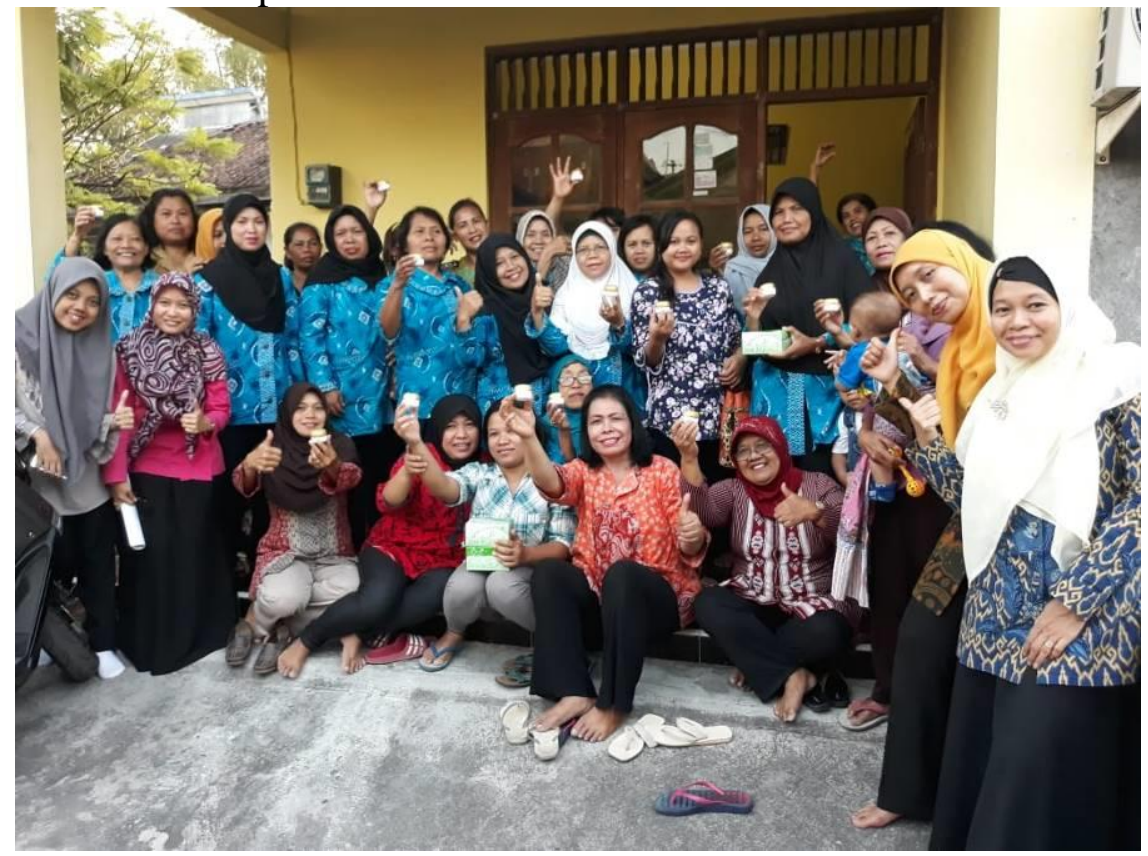

Gambar 5. Hasil pelatihan pembuatan deodoran

\section{PENUTUP}

Kegiatan pengabdian pelatihan pembuatan deodoran herbal alami di RW 22 RT 03 Nusukan, Banjarsari, Surakarta terlaksana dengan lancar. Rangkaian kegiatan meliputi sosialisasi, pemberian leaflet, demonstrasi dan praktik pembuatan deodorant herbal. Peserta antusias 
dengan pembuatan deodoran dengan inovasi wadah berupa deotube. Peserta berperan aktif dalam pelatihan dan mampu membuat produk secara mandiri.

\section{UCAPAN TERIMAKASIH}

Ucapan terimakasih kepada LPPM Universitas Setia Budi atas dana Hibah Pengabdian Kepada Masyarakat tahun 2018

\section{REFERENSI}

Agoes, A. 2010. Tanaman Obat Indonesia. Salemba Medica. Palembang

Arisandi, Y. dan Andriani, Y. 2008. Khasiat Tanaman Obat. Pustaka Buku Murah. Jakarta

Anief. (2005). Ilmu Meracik Obat. Yogyakarta:Gadjah Mada University Press.Hal 72 ,132

Dalimartha, S. 2003. Atlas Tumbuhan Obat Indonesia. Jilid 3. Puspa Swara. Jakarta

Dalimartha, S. 2004. Tumbuhan Obat Indonesia. Jilid 1. Trubus Agriwidya. Jakarta

Dalimartha, S. 2005. Tanaman Obat di Lingkungan Sekitar. Puspa Swara. Jakarta

Depkes RI. (1995). Materia Medika Indonesia. Jilid VI. Jakarta: Departemen Kesehatan RI. Hal. 319-325.

Ditjen POM. (1979). Farmakope Indonesia. Edisi III. Jakarta: Departemen Kesehatan RI. Hal. 33

Guenther, E. (1990). The Essential Oils. Penerjemah: Ketaren, R.S. Minyak Atsiri.

Guenther, E. (1990). The Essential Oils. Penerjemah: Ketaren, R.S. Minyak Atsiri.

Jilid III A. Jakarta: Penerbit Universitas Indonesia. Hal. 147-157.

Gunawan, D. dan Mulyani, S. (2004). Ilmu Obat Alam (Farmakognosi). Jilid I. Jakarta: Penerbit Penebar Swadaya. Hal. 123.

Hariana, A. 2008. Tumbuhan Obat dan Khasiatnya. Cetakan Kelima. Penebar Swadaya. Jakarta

Tranggano RI. Buku pegangan ilmu pengetahuan kosmetik. Jakarta: Gramedia pustaka utama. 2007.

\section{BIODATA PENULIS}

\section{Nama : Ika Nur Fitriani}

Nama instansi : Universitas Setia Budi

Tempat, tanggal lahir : Bantul, 31 Maret 1993

Pengalaman penelitian dan pengabdian masyarakat 3 tahun terakhir:

- Pengabdian Internal Pembuatan Deodoran Herbal Alami 